\title{
Minimum Ignition Energy of Aluminium Nanopowders as Engineered Nanomaterials (ENMs)
}

\author{
S. H. N. Zahari, R. Rusli*, A. Buang and K. Mohanan \\ Chemical Engineering Department, Universiti Teknologi PETRONAS, 32610 Seri \\ Iskandar, Perak, Malaysia \\ *Email: risza@utp.edu.my \\ Phone: +6053687567; Fax: +6053654088
}

\begin{abstract}
Enormous absence of knowledge regarding dust explosion involving Engineered Nanomaterials (ENMs) has led to the exploration on investigating the Minimum Ignition Energy (MIE) of selected ranges of sizes for aluminum nanopowders. Nanostructure owned by alumina definitely contributes to changes in its chemical as well as physical composition. Thus, testing on MIE determination was conducted on three different particle sizes of aluminum nanopowders; A1-100nm, Al-70nm, Al-40nm. The main aim of the project is to determine the relationship of the particle diameter with their respective MIE. The overall experimental procedure take place using 1.2L Hartmann tube explosion system based on ASTM E2019. Two different dust concentrations were tested $\left(250 \mathrm{~g} / \mathrm{m}^{3}\right.$ and $\left.500 \mathrm{~g} / \mathrm{m}^{3}\right)$ and the results showed that Al-40 $\mathrm{nm}$ have the lowest MIE values of less than $5 \mathrm{~mJ}$ for both concentrations. For Al-70nm, the MIE value at concentration equals to $250 \mathrm{~g} / \mathrm{m}^{3}$ is between $10 \mathrm{~mJ}$ and $33 \mathrm{~mJ}$, whereas the MIE is less than $10 \mathrm{~mJ}$ at concentration equals to $500 \mathrm{~g} / \mathrm{m}^{3}$. This contradicts with Al-100nm in which the MIE is between $100 \mathrm{~mJ}$ and $200 \mathrm{~mJ}\left(\mathrm{c}=250 \mathrm{~g} / \mathrm{m}^{3}\right)$ and between $33 \mathrm{~mJ}$ and $51 \mathrm{~mJ}\left(\mathrm{c}=500 \mathrm{~g} / \mathrm{m}^{3}\right)$. In overall, as particle size decreasing, the MIE is significantly decreasing at respective concentrations.
\end{abstract}

Keywords: Engineered nanomaterials; aluminium dust explosion; minimum ignition energy; nanopowders

\section{INTRODUCTION}

Nanotechnology appeared to be one of the fastest growing technologies and predicted to be implemented in vast range of applications. It comprises the manipulations of matter ranges from at least 1 to $100 \mathrm{~nm}$ [1] and titled as a key to the next revolution. Nanomaterials are built up from numerous tiny nanoparticles and can be classified into two categories; naturally occurring nanomaterials and synthetic nanomaterials [2]. The Engineered Nanomaterials (ENMs) fall in the synthetic nanomaterials category in which ENMs are being specifically synthesized and modified in order to meet certain needs of functions. The nano-structures owned by ENMs definitely affect their physical and chemical compositions such as they may carry specific sizes and shapes. Thus, ENMs are widely used in industries such as pharmaceutical, cosmetics, surfaces and coatings, medical drugs as well as food industries [3].

ENMs are identified as one of the important key elements in ensuring the success of nanotechnology applications. The toxicology aspects of nanoparticle dispersion has been thoroughly discussed among the researchers and mostly found in 
the publications and journals [4]. However, the explosibility aspects of ENM are very limited to be obtained from any research engines. The predictions regarding explosive potential of ENMs seem uncertain due to the difficulties in determining the dust classification. One of the important parameters involved in assessing the explosive potential of any substance or materials is minimum ignition energy (MIE). MIE can be categorized as one of the tool in determining the likelihood of occurrences for any explosion cases.

MIE is the minimum energy input required to initiate combustion and all flammable material including dusts have MIEs in which their dependencies are on their respective concentration, pressure and temperature [5]. The common experimental method used in evaluating the MIE value of combustible dust is by using a 1.2-L Hartmann apparatus and carried out in accordance with the Standard Test Method for Minimum Ignition Energy of a Dust Cloud in Air in ASTM E 2019 published by the American Society for Testing and Materials. Previous experiments conducted have proven that MIE is directly proportional to an increase in pressure and any increase detected in the concentration of nitrogen would also lead to a higher value of MIE. Generally, the value of MIE is identified to be slightly higher rather than the combustible gas at certain energy level [5].

An increase in dust concentration of any combustible dust would directly lead to the occurrences of dust explosion. Aluminum nanopowders are being classified as one of the combustible dust and history had shown that there are multiple cases of explosion involving these alumina nanopowders as the main contributor. The most recent aluminum dust explosion was reported takes place in an automotive parts factory at Kunshan, China. The tragic dust explosion lead to the death of 146 workers and 114 other workers were seriously injured [6].

On the other hand, aluminum nanoparticles are proven as highly effective catalyst and commonly practical in improving the heat combustion and combustion stability especially in solid rocket fuel application. The burning rate of aluminum in nano range is to be said can be up to approximately $35 \%$ higher compared to powders with the same element but with larger particle sizes [7]. Applications of aluminum nanoparticles in industrial sector can be said as an essential. Thus, further research and assessment on explosion characteristics particularly for nano-sized materials need to be done to promote a safer handling environment for these materials.

Therefore, this research aims to investigate the relationship between particle sizes of aluminum nanopowders with their respective minimum ignition energy (MIE) at two different concentrations; $250 \mathrm{~g} / \mathrm{m}^{3}$ and $500 \mathrm{~g} / \mathrm{m}^{3}$ focusing on three different particle sizes of aluminum nanopowders; Al-100 nm, Al-70 nm and Al-40 nm. Three different ranges of aluminum nanoparticles have been selected based on the definition of prefix nano- as mentioned earlier.

\section{EXPERIMENTAL SET UP}

Engineered Nanomaterials (ENMs) involved are aluminum with three different particle diameters (Al-40 nm, Al-70 nm, Al-100 nm) at two different concentrations $\left(250 \mathrm{~g} / \mathrm{m}^{3}\right.$ and $500 \mathrm{~g} / \mathrm{m}^{3}$ ). All samples were used without further purification or modifications. Aluminum nanopowders (Al, 99.99\%, metal basis) with diameter of $40 \mathrm{~nm}, 70 \mathrm{~nm}$ and $100 \mathrm{~nm}$ were purchased from US Research Nanomaterials, Inc. (USA). The samples are being kept in a desiccator for the purpose of excess moisture removal a da y before each experiment was being conducted. 
The aluminum nanopowders have been characterized by using a Variable Pressure Field Emission Scanning Electron Microscope- Energy Dispersive X-Ray (VP FESEM-EDX) (Model: Zeiss Supra55). This equipment allows surface examination down to nanometer scales in variable pressure model. The results of scanning images are illustrated in Figure 1, 2 and 3.

The determination of MIE for Al-40 nm, Al-70nm and Al-100 were carried out by using the 1.2 L Hartmann apparatus (Model: KH504). The MIE cloud apparatus used consists of two parts: the Hartmann explosion test apparatus and a spark generator. The technical parameters of the equipment are listed as in Table 1.

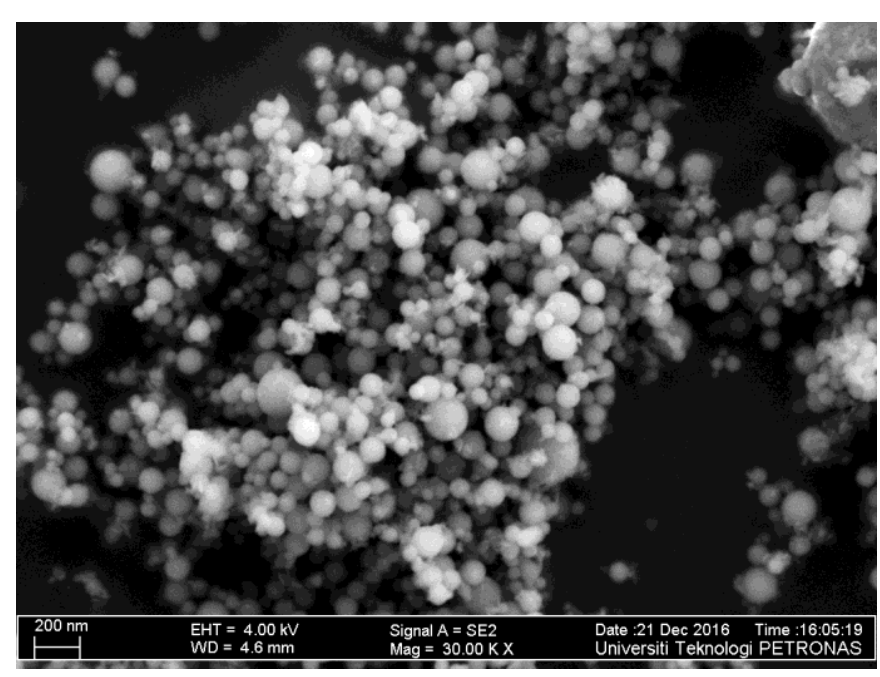

Figure 1. FESEM Image for Al-40 nm

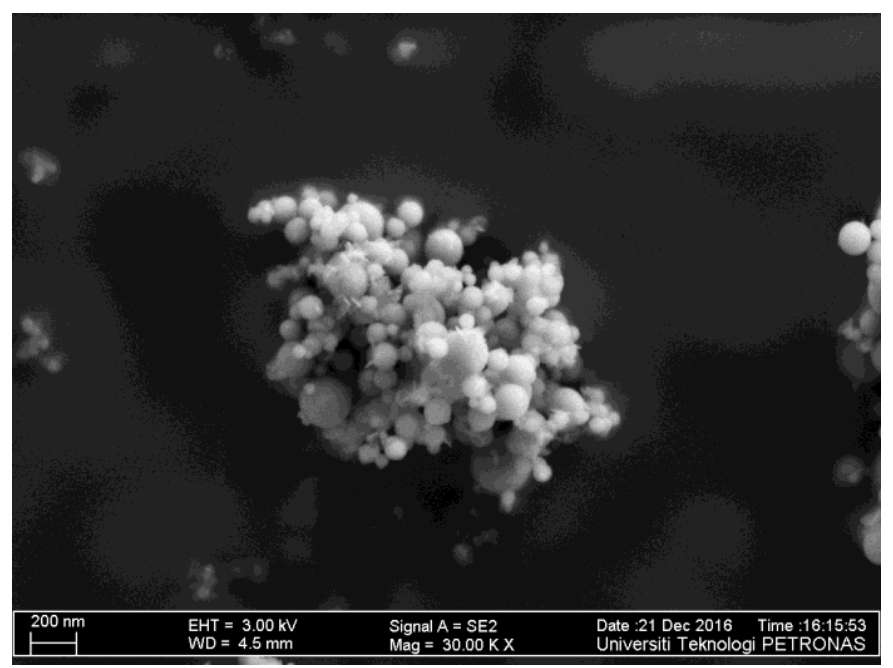

Figure 2. FESEM Image for Al-70 nm 


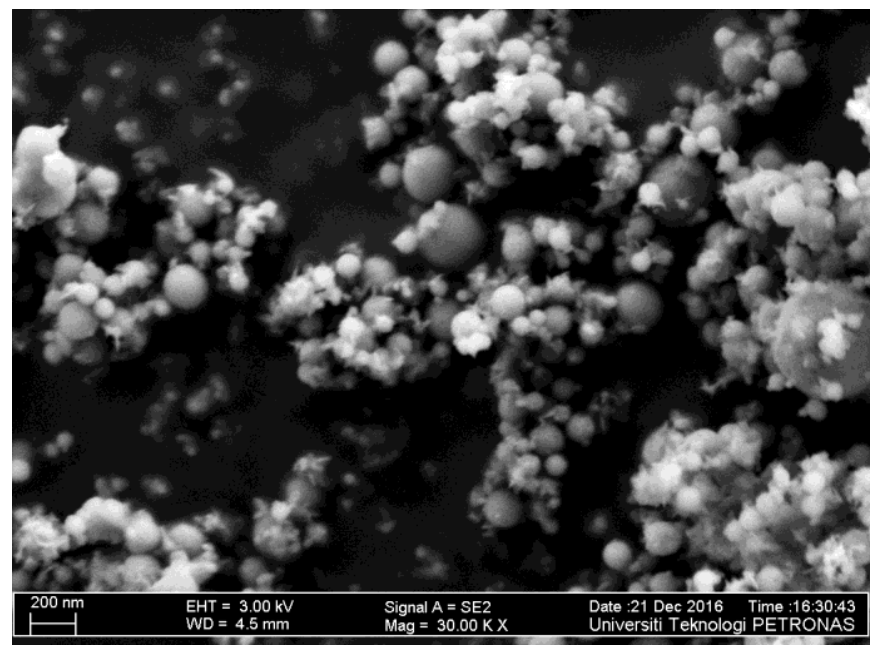

Figure 3. FESEM Image for Al-100 nm

Table 1. Technical parameters of MIE cloud apparatus

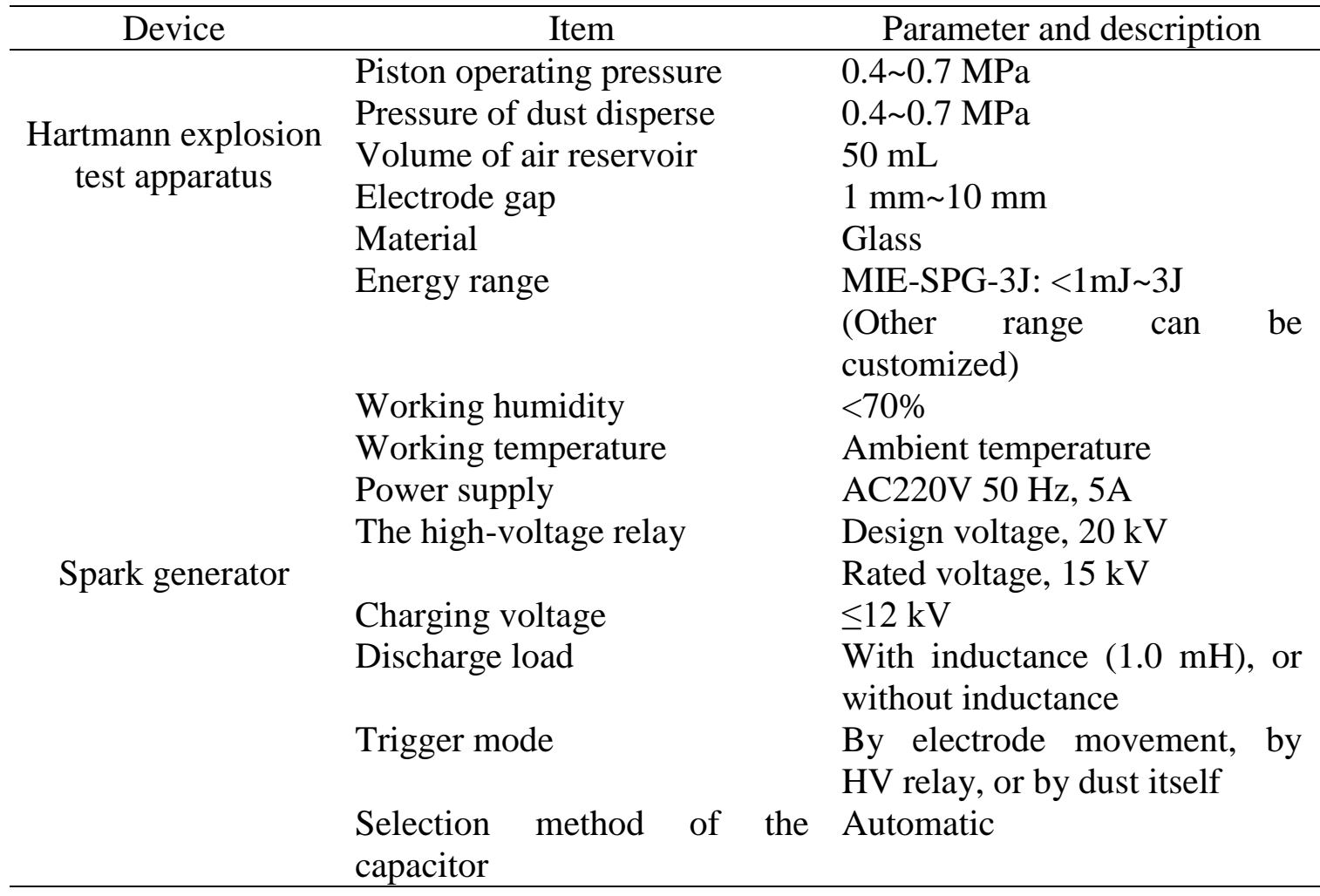

The entire experimental procedure in this study was carried out in accordance with ASTM E2019 Standard Test Method for Minimum Ignition Energy of a Dust Cloud in Air, EN 13821 Potentially explosive atmospheres-Explosion prevention and protection-Determination of minimum ignition energy of dust/air mixtures, IEC 1241-23 Electrical apparatus for use in the presence of combustible dust-Part 2: Test methodsSection 3: Method for determining minimum ignition energy of dust/air mixtures.

According to the standards followed, a specified weight of a dust powder is determined as being ignitable at a particular ignition energy if one test run resulted in an explosion in ten consecutive tests of the same dust powder weight and ignition energy. 
The value of MIE is between the NIE (no ignition energy) to IE (minimum energy for ignition) [8]. Figure 4 shows the schematic diagram of discharge circuit triggered by electrode movement.

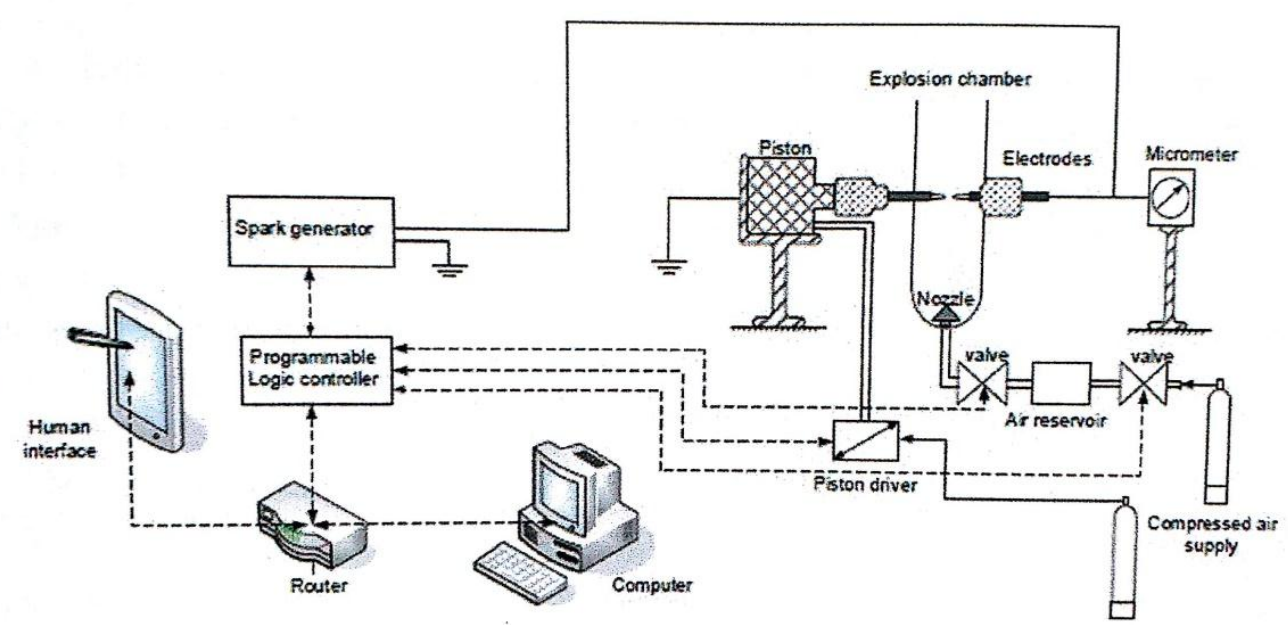

Figure 4. Schematic diagram of MIE cloud apparatus

The time delay condition in this experiment was $120 \mathrm{~ms}$ and the electrode gap is set to be at optimum of the order of $6 \mathrm{~mm}$. The MIE lies between the highest energy, $\mathrm{E}_{1}$, at which ignition fails to occur in a given times successive attempts to ignite the dustair-mixture, and the lowest energy, $\mathrm{E}_{2}$, at which ignition occurs once at least within the given times successive attempts as in Eq. (1) [6], [9].

$\mathrm{E}_{1}<\mathrm{MIE}<\mathrm{E}_{2}$

The main body of the apparatus is in the shape of a vertical cylinder and consists of an ignition device. The metal powders were initially placed at the bottom of the cylinders before compressed air are being supplied from the bottom to the top of the cylinder resulting in the formation of a dust cloud. The ignition took place as soon as the dust cloud is formed and leading to an explosion. The flames afterwards started to disperse in both directions of the cylinder's axes. The MIE cloud apparatus used in this project is being illustrated as in Figure 5. 


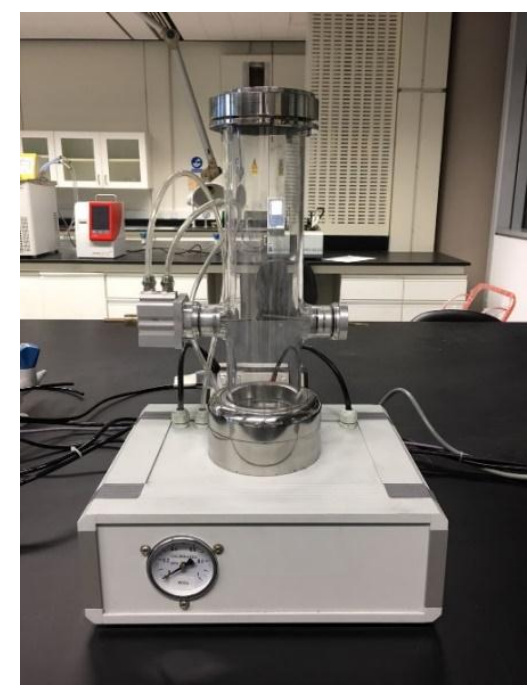

Figure 5. MIE cloud apparatus (Model: KH 504)

\section{RESULTS AND DISCUSSION}

The value of minimum ignition energy (MIE) can be spotted to be in the range of unsuccessful ignition to successful ignition. In case of all successful ignitions, the lowest ignition energy will be considered as minimum ignition energy. Figure 6 illustrates the MIE for aluminum dust $(100 \mathrm{~nm})$ and the result shows that the MIE lies between $100 \mathrm{~mJ}$ to $200 \mathrm{~mJ}$ at concentration $250 \mathrm{~g} / \mathrm{m}^{3}$. At concentration equals to 500 $\mathrm{g} / \mathrm{m}^{3}$, the MIE is spotted to be in the range of $33 \mathrm{~mJ}$ to $51 \mathrm{~mJ}$. For aluminum dust $(70$ $\mathrm{nm}$ ), the MIE is being demonstrated by Figure 7 in which MIE falls within the range of $10 \mathrm{~mJ}$ to $33 \mathrm{~mJ}$ at $250 \mathrm{~g} / \mathrm{m}^{3}$ whereas MIE is less than $10 \mathrm{~mJ}$ at concentration equals to $500 \mathrm{~g} / \mathrm{m}^{3}$. In the other hand, MIE for aluminum dust $(40 \mathrm{~nm})$ is shown to be in the range of less than $5 \mathrm{~mJ}$ for both concentrations in Figure 8.

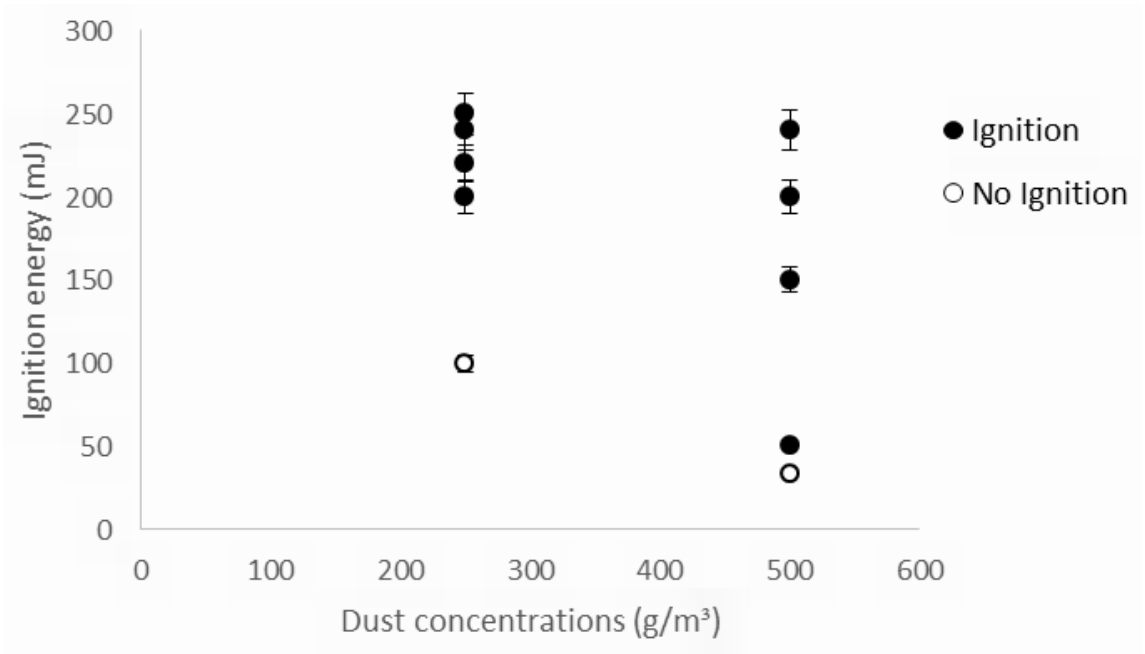

Figure 6. MIE for Al-100 nm 


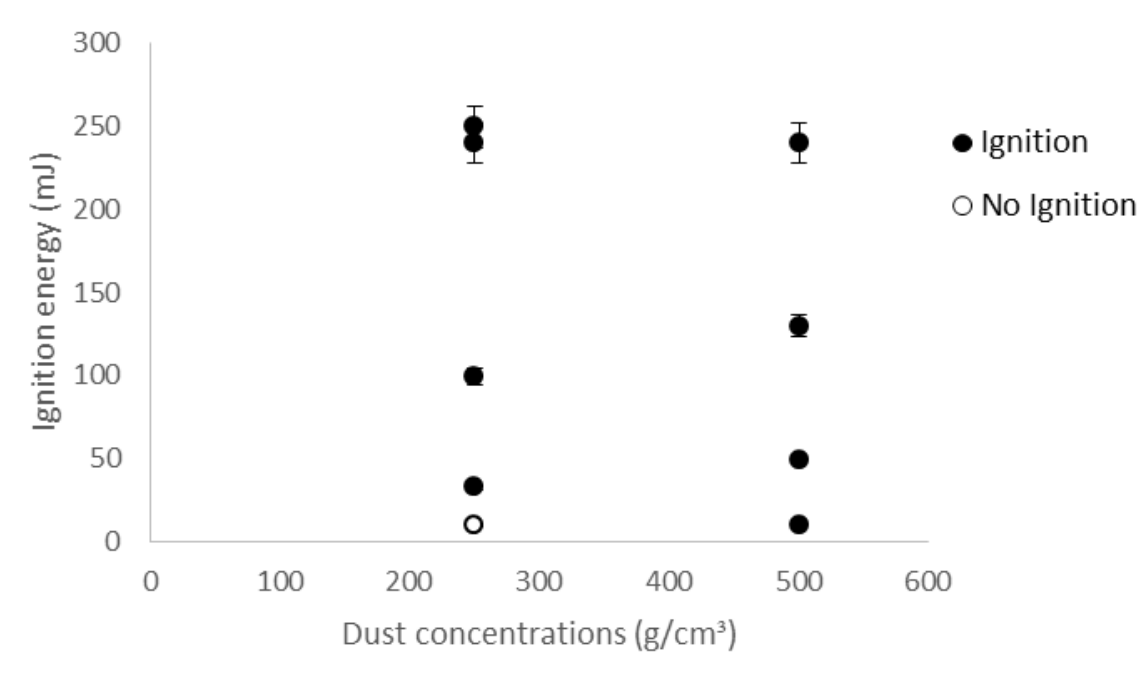

Figure 7. MIE for Al-70 nm

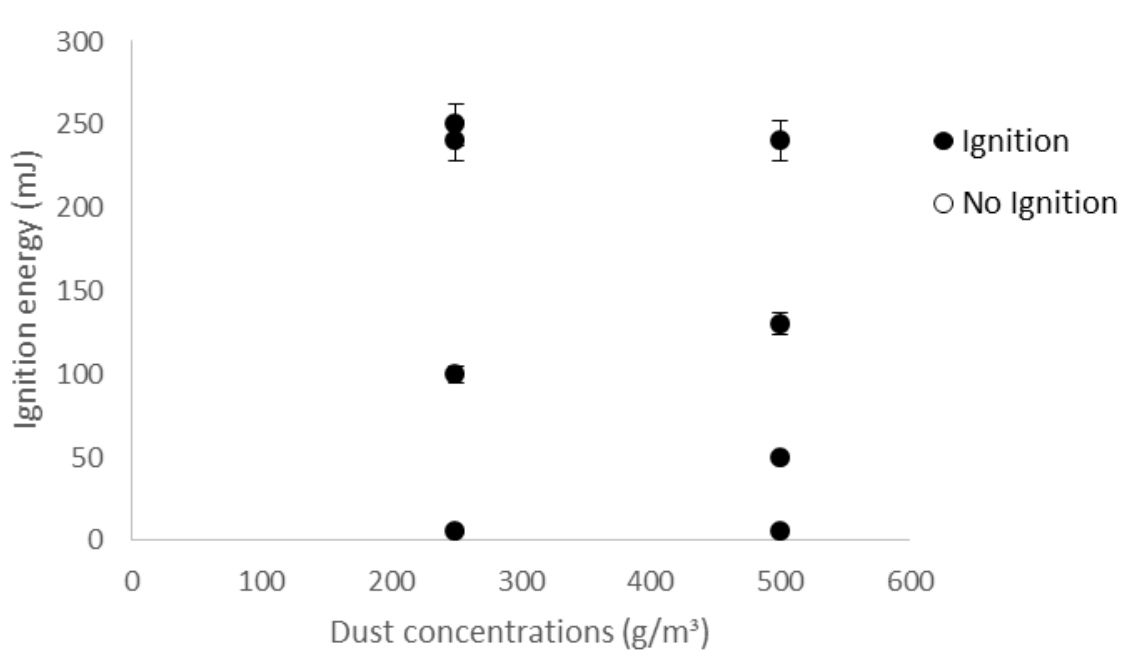

Figure 8. MIE for Al-40 nm

Aluminum nanopowders are expected to exhibit lower values of MIE since the powders exposed higher surface area due to its specific sizes in nano-range. Recent publications also mentioned that in the case of ignition sensitivity, the MIE for metal powders are significantly lower for nano particles when compared with micron particle [10]. The MIE for metallic nanopowders such as aluminum and iron (nominally 100$210 \mathrm{~nm}$ ) should be in the range of less than $1 \mathrm{~mJ}$ [11]. In overall, results show that an increase in the particle size would lead to a higher MIE. In the other words, the smaller the particle size, the MIE will be significantly decreasing. The data analyses of MIE determination for aluminum dust are being tabulated as in Table 2. 
Table 2. MIE for aluminum dust at respective concentrations

\begin{tabular}{lcc}
\hline \multirow{2}{*}{ Dust sample } & \multicolumn{2}{c}{ Dust concentration } \\
\cline { 2 - 3 } & $250 \mathrm{~g} / \mathrm{m}^{3}$ & $500 \mathrm{~g} / \mathrm{m}^{3}$ \\
\hline Aluminum $100 \mathrm{~nm}$ & $100 \mathrm{~mJ}<\mathrm{MIE}<200 \mathrm{~mJ}$ & $33 \mathrm{~mJ}<\mathrm{MIE}<51 \mathrm{~mJ}$ \\
Aluminum $70 \mathrm{~nm}$ & $10 \mathrm{~mJ}<\mathrm{MIE}<33 \mathrm{~mJ}$ & $\mathrm{MIE}<10 \mathrm{~mJ}$ \\
Aluminum $40 \mathrm{~nm}$ & $\mathrm{MIE}<5 \mathrm{~mJ}$ & $\mathrm{MIE}<5 \mathrm{~mJ}$ \\
\hline
\end{tabular}

Previous research mentioned that aluminum powders with diameters equal to 35 $\mathrm{nm}$ and $100 \mathrm{~nm}$ owned MIE values within the range of less than $1 \mathrm{~mJ}$ [12], but specific dust concentrations used during the experimental procedure were not being revealed. According to Table 2, MIE values tend to be lower for nanopowders at high concentrations. For instance, Al-100 nm exhibits MIE between $33 \mathrm{~mJ}$ and $51 \mathrm{~mJ}$ at concentrations equal to $500 \mathrm{~g} / \mathrm{m}^{3}$ whereas at concentration equals to $250 \mathrm{~g} / \mathrm{m}^{3}$, the MIE is between $100 \mathrm{~mJ}$ and $200 \mathrm{~mJ}$. From these data, the concentration of nanopowders plays an important role in determining the MIE itself. Therefore, the results gained are reliable enough provided the dust concentrations are being mentioned with respective diameters of aluminum.

MIE value acts as an indicator in determining the ignition sensitivity or likelihood of explosion occurrences [9]. In the other words, lower MIE value represents that the dust sample is extremely combustible. Explosive dust clouds that often happened in industry usually linked with the dust accumulation cases whereby the dust existed in the form of layers or deposits [13]. Intentional or unintentional reentrainment and re-dispersion of such deposits or layers have often been overlooked in assessing the hazards produced by these nanopowders. For that reason, the knowledge on specific MIE value for metal dust involved in any production have become the basis in performing the dust explosion hazard assessment.

In addition, the minimum ignition energy (MIE) data gained from this experiment can benefit various industries dealing with aluminum nanopowders as either their raw material or additives. For example, application of aluminum nanoparticles in solid rocket fuel plants to enhance the combustion will have large storage amount of these powders in their testing facilities. Therefore, taking consideration of the minimum ignition energy and lower explosive limit of nanopowders can help engineers to design the vessel or storage tank safe and efficiently. Moreover, sources of ignition such as flames, smoldering, hot surfaces, friction or impact and electrical discharge can be generated in industry activities which might initiate fire if dust clouds were to present at optimum concentration. Hence, data such as above can help engineers design the plant to have a safe working environment in handling aluminum nanoparticles.

\section{CONCLUSION}

Throughout this study, it has been found that the explosion likelihood of aluminum nanopowders significantly increase when the particle diameter is decreasing. This can be judged from the MIE values result from the testing and indicates that there is a high possibility for ignition risks in places where such powders are manufactured or utilized.

The MIE values for aluminum nanopowders in diameter of $100 \mathrm{~nm}, 70 \mathrm{~nm}$ and $40 \mathrm{~nm}$ measured in the experiments decreasing with their respective diameters at two different concentrations; $250 \mathrm{~g} / \mathrm{m}^{3}$ and $500 \mathrm{~g} / \mathrm{m}^{3}$. The research shall conclude as follows: 
a) MIE value for $\mathrm{Al}-40 \mathrm{~nm}$ is less than $5 \mathrm{~mJ}$ at both concentrations; $250 \mathrm{~g} / \mathrm{m}^{3}$ and $500 \mathrm{~g} / \mathrm{m}^{3}$.

b) MIE value for Al-70 nm is between $10 \mathrm{~mJ}$ and $33 \mathrm{~mJ}$ at concentration equals to $250 \mathrm{~g} / \mathrm{m}^{3}$ and less than $10 \mathrm{~mJ}$ at concentration equals to $500 \mathrm{~g} / \mathrm{m}^{3}$.

c) MIE value for Al-100 $\mathrm{nm}$ is between $100 \mathrm{~mJ}$ and $200 \mathrm{~mJ}$ at concentration equals to $250 \mathrm{~g} / \mathrm{m}^{3}$ and between $33 \mathrm{~mJ}$ and $51 \mathrm{~mJ}$ at concentration equals to $500 \mathrm{~g} / \mathrm{m}^{3}$.

For future study, the research shall be continued by assessing different types of metallic nanopowders and comparison should be made in order to determine the trend exhibit by these ENMs.

\section{ACKNOWLEDGEMENT}

This research was fully supported by Ministry of Higher Education, Malaysia under the cost centre FRGS 0153AB-i94 entitled "Investigating Dispersal and Explosive Behaviours of Engineered Nanomaterials (ENMs) and Centre of Advanced Process Safety (CAPS), Universiti Teknologi PETRONAS. The authors would like to thanks both organizations for providing technical and financial support in completing the current research work.

\section{REFERENCES}

[1] SCENIHR (Scientific Committee on Emerging and Newly Identified Health Risks). The scientific aspects of the existing and proposed definitions relating to products of nanoscience and nanotechnologies. 2007.

[2] Lohse S. Nanoparticles Are All Around Us. 2013.

[3] Beaumont J. The Potential of Nanotechnology. In: Partnership PF, editor. Wolfson School of Mechanical and Manufacturing Engineering, Loughborough University, Loughborough, Leics LE11 3TU 2005.

[4] Stebounova LV, Morgan H, Grassian VH, Brenner S. Health and safety implications of occupational exposure to engineered nanomaterials. Wiley Interdisciplinary Reviews: Nanomedicine and Nanobiotechnology. 2012;4:31021.

[5] Crowl DA, Louvar JF. Chemical process safety: fundamentals with applications 3rd ed: Pearson Education; 2011.

[6] Li G, Yang HX, Yuan CM, Eckhoff RK. A catastrophic aluminium-alloy dust explosion in China. Journal of Loss Prevention in the Process Industries. 2016;39:121-30.

[7] G. Young, H. Wang, Zachariah MR. Application of nanoaluminium/nitrocellulose mesoparticles in composite solid rocket propellants. Propellants, Explosives, Pyrotechnics. 2010;40.

[8] American Society for Testing and Materials (ASTM). E2019 Standard test method for minimum ignition energy of a dust cloud in air. 2001.

[9] Wu H-C, Chang R-C, Hsiao H-C. Research of minimum ignition energy for nano titanium powder and nano iron powder. Journal of Loss Prevention in the Process Industries. 2009;22:21-4.

[10] Eckhoff RK. Does the dust explosion risk increase when moving from $\mu \mathrm{m}-$ particle powders to powders of nm-particles? Journal of Loss Prevention in the Process Industries. 2011;25:448-59. 
[11] P.Holbrow, M.Wall, E.Sanderson, D.Bennett, W.Rattigan, R.Bettis, et al. Fire and explosion properties of nanopowders. In: Laboratory HaS, editor. HSE Report RR7822010.

[12] Wu H-C, Ou H-J, Hsiao H-C, Shih T-S. Explosion characteristics of aluminum nanopowders. Aerosol and Air Quality Research. 2010;10:38-42.

[13] Eckhoff RK. Are enhanced dust explosion hazards to be foreseen in production, processing and handling of powders consisting of nano-size particles? Journal of Physics: Conference Series. 2013;304. 